\title{
Corneal Langerhans Cell And Endothelium Changes In Patients With Herpetic Keratitis During Acute Phase Of The Disease And After 6 Months
}

\author{
Vilija Danileviciene ( $\sim$ vilija123@gmail.com ) \\ Lithuanian University of Helath Sciences https://orcid.org/0000-0001-5393-8965 \\ Reda Zemaitiene \\ Lithuanian University of Health Sciences \\ Vilte Marija Gintauskiene \\ Lithuanian University of Health Sciences \\ Irena Nedzelskiene \\ Lithuanian University of Health Sciences \\ Dalia Zaliuniene \\ Lithuanian University of Health Sciences
}

\section{Research article}

Keywords: Herpes simplex virus, keratitis, confocal microscopy, Langerhans cell, endothelium

Posted Date: June 13th, 2019

DOI: https://doi.org/10.21203/rs.2.10317/v1

License: (c) (i) This work is licensed under a Creative Commons Attribution 4.0 International License. Read Full License 


\section{Abstract}

Purpose. To describe corneal morphological changes by evaluating Langerhans cell (LC) and endothelium cell density using in vivo laser scanning confocal microscopy (LSCM) in herpes simplex virus (HSV) keratitis during acute phase of the disease and after 6 months, to compare with contralateral eyes, controls with previous history of herpes labialis and healthy controls. Methods $\mathrm{A}$ prospective clinical study included 79 patients with herpetic eye disease, 101 healthy patients with previous history of herpes labialis but no history of herpetic eye disease, and 89 patients with no history of any HSV diseases. All patients underwent a complete ophthalmological examination including LSCM of the central cornea, using the Heidelberg Retina Tomograph III Rostock Cornea Module. After 6 months, the same ophthalmological examination was performed for patients with herpetic eye disease. Serology tests of the serum to detect HSV 1/2 IgG and IgM using Virion Serion ELISA classic kit were performed. Results HSV affected eyes showed an increase in LC density when compared with contralateral eyes, herpes labialis, and healthy control groups (357.9 \pm 308.7 vs. $197.1 \pm 258.5$ vs. $62.9 \pm 72.6$ vs. $81.7 \pm 88.3$ ) ( $p<0.05$ ). Higher LC density and less density of corneal sub-basal nerve parameters were found $(\mathrm{p}<0.05)$. Endothelium density in HSV affected eyes did not differ from the contralateral eyes, but it was lower when comparing with herpes labialis patients and healthy controls $(2300.7 \pm 530.6$ vs. $2343.3 \pm 543.7$ vs. $2672.9 \pm 268.1$ vs. $2620.9 \pm 347.1)$ $(p<0.05)$. After 6 months, LC density in HSV affected eyes decreased but did not reach those of healthy controls $(p<0.05)$. Conclusions LSCM reveals a significant increase of LC and decrease of endothelium cell density in HSV affected corneas. The decrease in LC density is a clear, indirect sign of recovery, which can be used in clinical practice.

\section{Background}

Herpetic eye disease is one of the most common infections that cause corneal blindness. The incidence of HSV keratitis is approximately 1.5 million, worldwide, including 40,000 new cases of related blindness each year [1-3]. The disease is caused by HSV, which is widely spread in the human population. About 90 percent of the population over the age of 50 is infected with HSV. Herpetic eye disease mostly affects the anterior segment and manifests as an epithelial or stromal keratitis, endotheliitis, and/or iritis.

HSV is a linear, double-stranded deoxyribonucleic acid (DNA) virus belonging to the Herpesviridae family. During the first episode of HSV-1 infection, the virus replicates in the corneal epithelium cells, which are vulnerable to the direct viral cytopathic effect. When the infection recurs, the corneal stroma is exposed. Due to an inflammatory response, the cornea becomes cloudy and cicatrized. Stromal tissue swelling and loss of integrity is influenced by inflammatory cell infiltration, which is detected in the cornea [4].

Corneal cell interaction with HSV causes an inflammatory cascade with anti-inflammatory cell infiltration, which is responsible not only for clearance of the virus but also determines corneal damage due to corneal opacification, neovascularization, and corneal nerve loss.

The virus enters the cell by fusing with the cell membrane. After the entrance, the synthesis of cytokines begins: cells involved in the immune response, such as natural killers (NK), dendritic cells (DC), neutrophils, macrophages and lymphocytes, are attracted to the site of inflammation. Corneal epithelial cells and plasma dendritic cells (pDC) express toll-like receptors, which detect virus DNA [5]. Inflammatory cascade with anti-inflammatory cell infiltration is responsible not only for clearance of the virus but also determines corneal damage due to corneal opacification, neovascularization and corneal nerve loss [6].

$\mathrm{DC}$ are the most potent antigen presenting cells of the immune system to induce antiviral immune responses. They phagocytose viral particles and infected cells and deliver to the draining lymph nodes to generate an adaptive immune response [6]. A decrease of DC in the cornea determines later NK, monocytes, and chemokines migration to the site of infection, resulting in delayed virus removal [5]. LC are a population of DC that mediate antigen presentation. LC are discrete leukocyte population of professional, specialized antigen presenting cells (APCs) with an exceptional capacity for initiating T-lymphocyte responses and expression of major histocompatibility complex (MHC) class II antigens in the corneal epithelium [1-3].

In the acute phase of HSV keratitis LC are located at the level of the lower intermediate cells, basal cells, and sub-basal nerve plexus. During the active infection, a wide net with infiltration of LC can be found $[7,8]$.

Corneal endothelium is a single layer of cells on the inner surface of the cornea. Endothelial cells (EC) form a monolayer located at the Descemet's membrane in the posterior cornea. It plays a significant role in maintaining visual function: controls cornea hydration and transfers nutrients and other molecules from the aqueous humour [9]. As a result of aging, diseases, injury, or surgeries EC could

Page 2/8 
be damaged and influence corneal blindness [10]. The minimum density of corneal EC for normal functioning is thought to be around 500 cells/mm [11].

The main purpose of our study is to describe corneal morphological changes including LC and EC density in patients with herpetic eye disease and compare with data of contralateral, clinically unaffected eyes and control groups during acute phase of the disease and in 6 months. We compare the results not only with healthy controls, but also with patients, who previously have had herpes labialis.

\section{Methods}

In a prospective clinical study we included 269 patients (170 women (63.2\%) 99 men (36.8\%), mean age $59.0 \pm 8.5$ years, range 28.1 - 84.8). All patients were divided into 3 groups: 79 patients (38 women (58.1\%), 41 men (51.9\%) mean age $59.5 \pm 9.0$ years, range 28.1 - 76.0) with active unilateral herpetic eye disease, according to their clinical history and clinical examination, 101 healthy patients (72 women (71.3\%), 29 men (28.7\%), mean age $58.9 \pm 8.5$ years, range $43.0-84.8$ ) with previous history of herpes labialis and 89 patients ( 60 women $67.4 \%), 29$ men (32.6\%), mean age $58.5 \pm 7.9$ years, range $44.0-80.3$ ) with no history of HSV diseases. Patients with previous history of other ocular infection, trauma, contact lens wearing, diabetes mellitus, glaucoma and previous intraocular or refractive surgery were excluded from the study.

The study was approved by the Biomedical Research Ethics Committee 2015-07-09 No. BE-2-26 and 2017-01-26 Nr. P1-BE-226/2015.All subjects wrote informed consent to participate in the study. All patients underwent a complete ophthalmological examination, Cochet-Bonnet aesthesiometry and LSCM (Heidelberg Retina Tomograph 3 with the Rostock Cornea Module, Heidelberg Engineering $\mathrm{GmbH}$, Dossenheim, Germany) of the central cornea. Images of all the layers of the cornea were obtained and special attention was paid to the morphology of the dendritic cells and endothelium. LC were morphologically identified as bright cellular images with a branching morphology, located at the sub-basal nerve plexus layer. We counted LC and EC density using software analysis of the instrument, by averaging the number of cells from the 3 most representative images of central cornea. The cells were counted manually within a region of standardized dimensions $(250 \times 250 \mu \mathrm{m})$ and the result was given as cells $/ \mathrm{mm}^{2}\left(\mathrm{cell} / \mathrm{mm}^{2}\right)$ [12].

The corneal nerves analysis was performed using automated Corneal Nerve Fibre Analyser ACCMetrics V.2 The software automatically extracts and quantifies nerve fibre metrics in images obtained using the Heidelberg HRT III corneal confocal microscope with $384 \times 384$ pixels and the field of view of $400 \times 400 \mu \mathrm{m} 2$ (resolution: 400/384=1.0417 $\mu \mathrm{m}$ ). It quantifies the corneal nerve fibre length - the total length of nerves $\mathrm{mm} / \mathrm{mm}^{2}$, nerve fibre density - the number of fibres $/ \mathrm{mm}^{2}$, nerve branch density - the number of branch points on the main fibres $/ \mathrm{mm}^{2}$, nerve fibre total branch density - the total number of branch points/mm² [13-17].

After 6 months from the first clinical examination, the same ophthalmological investigation was repeated, and the data were compared with the primary test results.

For all patients, serology tests of the serum to detect HSV 1/2 IgG and IgM using Virion Serion ELISA classic kit were performed (sensitivity and specificity $>98 \%$ ). Negative results were when IgG or IgM concentrations were $<20 \mathrm{U} / \mathrm{ml}$, possible 20-30 U/ml, positive $>30 \mathrm{U} / \mathrm{ml}$. IgG positive result were divided in to two groups: I - when concentration was less than $10000 \mathrm{U} / \mathrm{ml}$, II-when concentration was more than $10000 \mathrm{U} / \mathrm{ml}$.

The statistical analysis was performed with SPSS programme. All parametric data were expressed as the mean and standard deviation. Kolmogorov-Smirnov test was used for determination of quantitative data distribution. The results were analysed by Kruskal-Wallis and Mann-Whitney tests. The Kruskal-Wallis test was applied to compare the scores of more than 2 independent groups and the Mann-Whitney - for the scores of two independent groups. Differences on dependent variables were analysed by the Wilcoxon signed-rank test. $\chi^{2}$ tests were used for comparing frequencies of qualitative variables. In order to assess minimally false negative and minimally false positive results with the greatest accuracy, the method of ROC (Receiver Operating Characteristics) curve was used. Logistic regression analysis was performed to determine the odds ratio predictive value. Differences were considered statistically significant, when $p$ values $<0.05$.

\section{Results}


79 patients (42 OD, 27 OS ( $p>0.05))$ with active herpetic eye disease, including epithelial $(n=48)$, stromal $(n=15)$, or endothelial keratitis $(n=16), 101$ patients with previous history of herpes labialis, but no history of herpetic eye disease, and 89 patients with no history of any HSV diseases were analysed and compared. Demographic data of all groups and subgroups are presented in Table 1.

HSV affected eyes showed an increase in LC density when compared with contralateral eyes, herpes labialis, and healthy control groups ( $357.9 \pm 308.7$ vs. $197.1 \pm 258.5$ vs. $62.9 \pm 72.6$ vs. $81.7 \pm 88.3)(p<0.05)$. The results of contralateral eyes were also significantly different from the control groups $(p<0.05)$.

EC density in HSV affected eyes did not differ from the contralateral eyes, but it was lower when comparing with herpes labialis patients and healthy controls $(2300.7 \pm 530.6$ vs. $2343.3 \pm 543.7$ vs. $2672.9 \pm 268.1$ vs. $2620.9 \pm 347.1)(p<0.05)$. The lowest LC and EC density were in the endothelial HSV keratitis subgroup, but the result was not statistically significant $(p>0.05)$. There was no significant difference of LC and EC density between herpes labialis and healthy control group eyes $(p>0.05)$. Data of all groups and subgroups are presented in Table 2.

There was a negative correlation between LC and sub-basal nerve parameters (corneal nerve fibre length, nerve fibre density, nerve branch density, and nerve fibre total branch density): higher LC density and less density of corneal sub-basal nerve parameters determines less corneal sensation $(p<0.05)$.

The mean time from the beginning of herpetic eye disease until the patient got to our hospital did not influence the LC and EC parameters ( $p>0.05)$. There was no correlation between LC and EC density and herpetic keratitis frequencies, herpes labialis manifestation, HSV IgM and IgG titers $(p>0.05)$.

After 6 months, LC density in HSV affected eyes and contralateral eyes had decreased, but it did not reach that of the herpes labialis group and healthy controls $(p<0.05)$. EC density in HSV affected eyes did not change (Table 3 ).

After 6 months, sub-basal nerve parameters and corneal sensitivity had increased but did not reach the parameters of contralateral eyes $(p<0.05)$.

Cornea edema was seen in $61.5 \%$ of eyes during active herpetic eye disease and in $16.4 \%$ of eyes during follow. Keratic precipitates had decreased from $60.8 \%$ of eyes before to $17.9 \%$ after 6 months. Cornea neovascularization had increased from $13.9 \%$ to $20.9 \%$. $7.5 \%$ of cases had a reactivation of keratitis after 6 months, with a superficial epithelium defect or even corneal ulceration. LC or EC density during active herpetic eye disease did not affect the corneal clinical manifestation after 6 months $(p>0.05)$.

\section{Discussion}

LC which appear at the level of the basal epithelial cells and between the fibres of the sub-basal nerve plexus, have been postulated to represent dendritic cells. These cells initiate and control the transition of local innate to adaptive immune responses. During viral infection, corneal LC migrate to the site of tissue damage. The influx of LC heralds the immune stromal response during reactivation of herpetic keratitis in experimental HSK animal models [18]. The migration of LC is important in the pathogenesis of HSV keratitis. LC migrate from the limbus and the peripheral region of the epithelium, preceding the development of HSV keratitis. The peak of LC in the cornea is 10 to 14 days after the HSV infection and continues until day 21 after infection. It has also been shown that LC migration into the central cornea before HSV infection enhances the delayed type hypersensitivity response to HSV antigens and increases the severity of HSV keratitis infection [19].

Our study demonstrated a significant increase of LC density in HSV affected eyes and coincide with the findings of M. C. Mocan and T. Wang $[20,21]$. A little increase was also seen in contralateral eyes comparing with healthy controls and patients with previous history of herpes labialis. After 6 months, LC density in affected eyes and contralateral eyes had decreased but it did not reach that of the herpes labialis group and healthy controls. Increased LC influences less density of corneal sub-basal nerve parameters, such as corneal nerve fibre length, nerve fibre density, nerve branch density, and nerve fibre total branch density, which results in less corneal sensation. A strong and significant correlation between an increased number of LC in the central cornea and decreased subbasal corneal nerves, suggests a potential interaction of the immune and nervous systems during corneal infections [22]. A close relation between nerves and LC has been demonstrated in the skin, where LC can be modulated by neuropeptides released from 
epidermal nerves [23,24]. Recent evidence suggests that corneal DC may play a role in the induction of latency and the severity of chronic recurrent herpetic stromal keratitis [25].

HSV is able to reach corneal endothelium, causing endothelial cell loss and permanent corneal swelling. Recurrent episodes may eventually lead to corneal scarring, opacities, and irregular astigmatism. Results of our study showed that EC density statistically did not differ between the eyes of patients with herpetic eye disease, but it was lower when compared with herpes labialis patients and healthy controls. EC density in HSV affected eyes stayed lower comparing with control groups 6 months later. Our data coincide with the results described by RT. Muller et al. [26]. Hillenaar T et al. also have found an endothelium density decrease during HSV infection. However, they described the results being significantly different comparing HSV affected and contralateral eyes, when the EC density in contralateral eyes was close to normal [18].

Epithelial keratitis was found with dendritic infiltrates and was characterized by epithelial blisters filled with fluid. For these patients LSCM showed swollen or necrotic epithelial cells with decreased sub-basal nerve fibres and a large number of LC infiltration surrounding them. In some cases, we could see anterior stroma damage, with enhanced reflectivity of the cells and difficulty in seeing cell nuclei. Herpes stromal keratitis was diagnosed in patients withstromal opacities or destruction, ulcerative infiltrates and neovascularization. Patients with swelling of the central part of the stroma with the ring infiltrate and precipitate on corneal endothelium had endothelial keratitis. In stromal and endothelium keratitis LSCM showed unclear structure of the stroma with a large number of LC and other inflammatory cell infiltrations. We could see many keratic precipitates with infiltration of inflammatory cells in the endothelium. In some patients we found pseudoguttata with enlarged intercellular gaps, spot holes, and a loss of endothelium cell boarders. Similar findings were described in T. Hillenaar et al. study. They also described endothelial involvement in different infectious and non-infectious corneal disorders [18].

A limitation of our study may be related to unequal number of patients between HSV keratitis subgroups. We evaluated only the central part of the cornea with LSCM, which is a contact diagnostic tool and can cause an ocular discomfort with eye movements, leading to blur images.

During the study we found LC and EC density changes in patients with herpetic eye disease, compared with contralateral, clinically unaffected eyes, herpes labialis patients and healthy controls during acute phase of the disease and after 6 months. The correlation between LC density and corneal sub-basal nerve parameters was found. To our knowledge, so far, longitudinal studies that have analyzed this data, and studies that have compared the results between HSV keratitis and herpes labialis patients have not been performed. The results of our study could be informative for clinical practice as a part of diagnostic procedures, which help to diagnose HSV keratitis and to evaluate the severity of the infection.

\section{Conclusions}

In conclusion, LSCM is an effective tool for detecting LC infiltration and endothelium changes in HSV affected corneas. Our findings demonstrated LC infiltration in HSV affected corneas. An increase was also seen in contralateral eyes comparing with healthy controls and patients with previous history of herpes labialis. LC density in affected eyes and contralateral eyes had decreased 6 months later but it did not reach that of the herpes labialis group and healthy controls. The decrease in LC density is a clear, indirect sign of recovery, which can be used in clinical practice. Endothelium density in HSV affected eyes did not differ from the contralateral eyes, but it was lower when comparing with herpes labialis patients and healthy controls.

\section{Abbreviations}

LC-Langerhans cells; LSCM-laser scanning confocal microscopy; HSV-herpes simplex virus; DNA-double-stranded deoxyribonucleic acid; NK-natural killers; DC-dendritic cells; pDC-plasma dendritic cells; APCs-antigen presenting cells; MHC-major histocompatibility complex; EC-endothelial cells.

\section{Declarations}

Ethics (and consent to participate) 
The study was approved by Biomedical Research Ethics Committee. Written informed consent was obtained from all subjects after a detailed explanation of the purpose of the study.

Consent for publicasion

Not applicable as the study does not identify the subjects.

Competing interests

The authors declare that they have no competing interests.

Authors' contributions

VD, RZ and DZ accomplished the design of the study, collecting and interpreting the data, preparing the manuscript. VMG performed immunological examination, IN performed statistical analysis. All authors read and approved the final manuscript.

Availability of data and materials

All the data supporting our findings is contained within the manuscript.

Funding

The study was funded by the Lithuanian University of Health Sciences. It does not influence the article, the decision to submit it for publication and do not accept any responsibility for the content.

Acknowledgements

Not Applicable.

\section{References}

1. Hamrah P, Zhang Q, Liu Y, Dana MR. Novel characterization of MHC class II-negative population of resident corneal Langerhans cell-type dendritic cells. Invest Ophthalmol Vis Sci.2002 Mar;43(3):639-46.

2. Rosenberg ME, Tervo TM, Müller LJ, et al. In vivoconfocal microscopyafter herpes keratitis. Cornea. 2002 Apr;21(3):265-9.

3. Steinman RM. The dendritic cell system and its role in immunogenicity. Annu Rev Immunol.1991;9:271-96.

4. Maertzdorf J, Albert DM. IL-17 Expression in Human Herpetic Stromal Keratitis:Modulatory Effects on Chemokine Production by Corneal Fibroblasts. J Immunol 2002: 169:5897-5903.

5. Rowe AM,St Leger AJ,Jeon S et al. Herpes Keratitis. Prog Retin Eye Res. 2013 Jan;32:88-101.

6. Lobo AM, Agelidis AM, Shukla D. Pathogenesis of herpes simplex keratitis: The host cellresponse and ocular surface sequelae to infection and inflammation. Ocul Surf.2019 Jan;17(1):40-49.

7. Guthoff RF, Zhivov A, Stachs O. In vivoconfocalmicroscopy, an inner vision of the cornea - a major review. Clin Exp Ophthalmol. 2009 Jan;37(1):100-17.

8. Jester JV, Morishige N, BenMohamed L, et al. ConfocalMicroscopicAnalysis of a Rabbit Eye Model of HighIncidence Recurrent HerpesStromal Keratitis. Cornea. 2016 Jan;35(1):81-8.

9. Bourne WM. Biologyof the cornealendothelium in health and disease. Eye (Lond). 2003 Nov;17(8):912-8.

10. Liu Y, Sun H, Hu M, et al. HumanCornealEndothelial Cells Expanded In Vitro Are a Powerful Resource for TissueEngineering. Int J Med Sci. 2017 Feb 7;14(2):128-135.

11. Molecular Biology of Eye Disease Andrew J. Hertsenberg, James L. Funderburgh, in Progress in Molecular Biology and Translational Science, 2015

12. Zhivov A, Stave J, Vollmar B, et al. In vivo confocal microscopic evaluation of Langerhans cell density and distribution in the normal human corneal epithelium. Graefes Arch Clin Exp Ophthalmol.2005 Oct;243(10):1056-61.

13. An Automatic Tool for Quantification of Nerve Fibres in Corneal Confocal Microscopy Images. Chen, X. et al. (2016) IEEE Transactions on Biomedical Engineering. in preprint 
14. Petropoulos IN, Alam U, Fadavi H, Marshall A, Asghar O, Dabbah MA, et al.Rapid automated diagnosis of diabetic peripheral neuropathy with in vivo corneal confocal microscopy. Investigative ophthalmology \& visual science2014; 55:2071-2078.

15. Petropoulos IN, Manzoor T, Morgan P, Fadavi H, Asghar O, Alam U, et al.Repeatability of in vivo corneal confocal microscopy to quantify corneal nerve morphology. Cornea2013; 32:e83-89.

16. Chen X, Graham J, Dabbah MA, Petropoulos IN, Ponirakis G, Asghar O, et al.Small nerve fiber quantification in the diagnosis of diabetic sensorimotor polyneuropathy: comparing corneal confocal microscopy with intraepidermal nerve fiber density. Diabetes Care2015; 38:1138-1144.

17. Tavakoli M, Ferdousi M, Petropoulos IN, Morris J, Pritchard N, Zhivov A, et al.Normative values for corneal nerve morphology assessed using corneal confocal microscopy: a multinational normative data set. Diabetes Care2015; 38:838-843.

18. Hillenaar T, Weenen C, Wubbels RJ, et al. Endothelial Involvement in Herpes Simplex Virus Keratitis: An In Vivo Confocal Microscopy Study. Ophthalmology. 2009 Nov;116(11):2077-86.e1-2.

19. Kwon MS, Carnt NA, Truong NR, et al. Dendritic cells in the cornea during Herpes simplex viral infection and inflammation. Surv Ophthalmol. $2018 \mathrm{Jul}$ - Aug;63(4):565-578.

20. Mocan MC, Irkec M, Mikropoulos DG, et al. In vivo confocal microscopic evaluation of the inflammatory response in nonepithelial herpes simplex keratitis. Curr Eye Res. 2012 Dec;37(12):1099-106.

21. Wang T, Dong M, Jiang Y, et al. Role of Dendritic Cells and Inflammatory Cells in Herpetic Endotheliitis: Analysis Using In Vivo Confocal Microscopy. Cornea. 2018 Jun;37(6):748-754.

22. Shaheen B, Bakir M, Jain S. Corneal Nerves in Health and Disease. Surv Ophthalmol. 2014 May-Jun; 59(3): 263-285.

23. Hosoi J, Murphy GF, Egan CL, et al. Regulation of Langerhans cell function by nerves containing calcitonin gene-related peptide. Nature 1993; 363:159-63.

24. Asahina A, Hosoi J, Grabbe S, et al. Modulation of Langerhans cell function by epidermal nerves. J Allergy Clin Immunol 1995; 96:1178-82.

25. Mott KR, Underhill D, Wechsler SL, et al.. Lymphoid-related CD11C+ CD8alpha+ dendritic cells are involved in enhancing herpes simplex virus type 1 latency. J Virol. 2008;82:9870-9879.

26. Müller RT, Pourmirzaie R, Pavan-Langston D, et al. In Vivo Confocal Microscopy Demonstrates Bilateral Loss of Endothelial Cells in Unilateral Herpes Simplex Keratitis. Invest Ophthalmol Vis Sci. 2015 Jul; 56(8): 4899-4906.

\section{Tables}

Table 1. Demographic data of patients with HSV keratitis and control groups.

\begin{tabular}{|l|c|c|c|c|c|c|}
\hline \multirow{2}{*}{ Parameters } & \multicolumn{3}{|c|}{ HSV keratitis } & \multirow{2}{*}{ Total } & Herpes labialis group & \multirow{2}{*}{ Healthy controls } \\
\cline { 2 - 6 } & Epithelial & Stromal & Endothelial & & & \\
\hline Patients, $n$ & 48 & 15 & 16 & 79 & 101 & 59 \\
\hline Age (years) (mean \pm SD) & $61.0 \pm 8.9$ & $55.7 \pm 8.1$ & $57.2 \pm 11.4$ & $59.9 \pm 9.0$ & $58.9 \pm 8.5$ & $43.5 \pm 7.9$ \\
\hline Age range (years) & $28.1-75.9$ & $38.3-66.3$ & $28.6-70.0$ & $28.1-76.0$ & $43-84.8$ & $44-80.3$ \\
\hline $\begin{array}{l}\text { Sex, } n \\
\text { (male/female) }\end{array}$ & $29 / 19$ & $4 / 11$ & $5 / 8$ & $38 / 41$ & $72 / 29$ & $60 / 29$ \\
\hline
\end{tabular}

There was no difference of age and sex between groups ( $p>0.05)$.

Table 2. Quantitative analysis of LC and EC density of patients with HSV keratitis and control groups. 


\begin{tabular}{|c|c|c|c|c|c|c|c|}
\hline & \multicolumn{3}{|c|}{ HSV keratitis } & \multirow{2}{*}{$\begin{array}{l}\text { Total } \\
\mathrm{n}=79\end{array}$} & \multirow{2}{*}{$\begin{array}{l}\text { Contralateral eye } \\
\qquad \mathrm{n}=79\end{array}$} & \multirow{2}{*}{$\begin{array}{l}\text { Herpes labialis } \\
\text { group } \\
\mathrm{n}=101\end{array}$} & \multirow{2}{*}{$\begin{array}{l}\text { Healthy controls } \\
\qquad \mathrm{n}=89\end{array}$} \\
\hline & $\begin{array}{c}\text { Epithelial } \\
\mathrm{n}=48\end{array}$ & $\begin{array}{c}\text { Stromal } \\
\mathrm{n}=15\end{array}$ & $\begin{array}{l}\text { Endothelial } \\
\qquad \mathrm{n}=16\end{array}$ & & & & \\
\hline $\begin{array}{c}\mathrm{LC} \\
\text { cell } / \mathrm{mm}^{2} \\
\end{array}$ & $371.9 \pm 358.4^{a b c}$ & $355.2 \pm 234.5^{\mathrm{def}}$ & $304.5 \pm 201.2^{g h i}$ & $357.1 \pm 312.8^{\mathrm{jkl}}$ & $197.1 \pm 258.5^{\text {adgjmn }}$ & $62.9 \pm 72.6^{\text {behkm }}$ & $81.7 \pm 88.3^{\text {cfiln }}$ \\
\hline $\begin{array}{c}\text { EC } \\
\text { cell } / \mathrm{mm}^{2}\end{array}$ & $2420.3 \pm 467.6^{\mathrm{ab}}$ & $2664.7 \pm 120.2$ & $2127.3 \pm 235.7^{\mathrm{cd}}$ & $2405.1 \pm 435.2^{\mathrm{ef}}$ & $2398.2 \pm 506.6^{g h}$ & $2672.9 \pm 268.1^{\text {aceg }}$ & $2620.9 \pm 347.1^{\text {bdfh }}$ \\
\hline
\end{tabular}

Values reported as mean $\pm \mathrm{SD}$

Table 3. Quantitative analysis of LC and EC density changes during follow up of patients with HSV keratitis

\begin{tabular}{|l|l|l|l|l|l|l|}
\hline \multirow{2}{*}{ Parameters } & \multicolumn{2}{|l|}{ HSV affected eye } & \multicolumn{2}{l|}{ Contralateral eye } & \multirow{2}{*}{ Herpes Labialis group } & \multirow{2}{*}{ Healthy controls } \\
\cline { 2 - 6 } & First visit & Follow up & First visit & Follow up & \\
\hline LC cell $/ \mathrm{mm}^{2}$ & $357.9 \pm 308.7^{\text {ab1 }}$ & $221.7 \pm 195.1^{\text {ab6ce }}$ & $197.1 \pm 258.5^{\text {ab1 }}$ & $143.5 \pm 149.5^{\text {ab6df }}$ & $62.9 \pm 72.6^{\text {cd }}$ & \\
\hline EC cell $/ \mathrm{mm}^{2}$ & $2300.7 \pm 530.6$ & $2374.0 \pm 483.6^{\text {ce }}$ & $2343.3 \pm 543.7$ & $2367.8 \pm 524.5^{\text {df }}$ & $2672.9 \pm 268.1^{\text {cd }}$ & $2620.9 \pm 347.1^{\text {ef }}$ \\
\hline & & & & & \\
\hline
\end{tabular}

a - $p$ value between parameters of first visit and follow up;

b1 - p value between parameters of HSV affected and contralateral eyes during first visit;

b6 - p value between parameters of HSV affected and contralateral eyes during follow up by Wilcoxon test;

c - p value between parameters of HSV affected eye during follow up and herpes labialis group;

d - p value between parameters of contralateral eyes during follow up and herpes labialis group;

e - p value between parameters of HSV affected eye during follow up and healthy controls;

f - p value between parameters of contralateral eyes during follow up and healthy controls by Mann-Whitney test. 